\title{
Atrial fibrillation: an update on management
}

\section{Craig J McCallum \\ Cardiology registrar \\ Deep Chandh Raja \\ Cardiologist \\ Rajeev Kumar Pathak \\ Associate professor \\ Cardiac Electrophysiology \\ Unit, Department of \\ Cardiology, Canberra \\ Hospital and Health \\ Services, Australian \\ National University}

\section{Keywords}

antiarrhythmic drugs, anticoagulants, apixaban, catheter ablation,

dabigatran, rivaroxaban, thromboembolism

Aust Prescr 2019;42:186-91

https://doi.org/10.18773/ austprescr.2019.067

\section{SUMMARY}

Atrial fibrillation carries a markedly increased risk of stroke and left ventricular dysfunction, and is associated with reduced quality of life.

In light of the potential for poor outcomes and the likely understated presence of silent atrial fibrillation, opportunistic screening should be carried out in general practice.

Modifying the risk factors for atrial fibrillation is the cornerstone of management with adjuvant drug therapy to help maintain sinus rhythm, control the ventricular rate and reduce the risk of cerebral thromboembolism.

The need for anticoagulant therapy can be assessed by using the revised $\mathrm{CHA}_{2} \mathrm{DS}_{2}-\mathrm{VASc}$ score. Direct oral anticoagulants are now preferred to warfarin in those who qualify for their use.

Catheter ablation is an effective option to improve survival in patients with left ventricular dysfunction. It also improves quality of life and reduces arrhythmia-related hospital admissions.

\section{Introduction}

Atrial fibrillation is the most common arrhythmia detected in clinical practice and accounts for over $30 \%$ of hospital admissions for cardiac rhythm problems.' The burden of disease appears to be increasing with higher prevalence and rates of atrial fibrillation-related hospital admissions. This illustrates the need for a renewed approach to its management.

\section{Epidemiology}

The prevalence of atrial fibrillation in Australia is $2-4 \%$, with a predominance in older people. ${ }^{3}$ This is likely to be an underestimation because silent atrial fibrillation (asymptomatic, subclinical) has not been taken into account. Most atrial fibrillation in Australia is non-valvular. ${ }^{4}$

Atrial fibrillation is associated with a significant increase in the long-term risk of stroke (2-5-fold higher than matched patients without atrial fibrillation), heart failure, impaired quality of life and all-cause mortality. It is important for GPs to recognise the strong association of certain risk factors with atrial fibrillation. These predominantly include obesity, obstructive sleep apnoea, hypertension, 5,6 valvular heart disease and genetic predisposition.7,8

\section{Classification}

Classification of atrial fibrillation according to duration of the arrhythmia is shown in Box 1.

Valvular atrial fibrillation is only considered an entity if the patient has moderate to severe mitral stenosis or a mechanical heart valve. All other forms of atrial fibrillation are referred to as 'non-valvular atrial fibrillation'. This distinction influences the choice of anticoagulant therapy. ${ }^{3}$

\section{Screening of patients for atrial fibrillation}

Silent atrial fibrillation is present in around $10 \%$ of patients who have an ischaemic stroke. ${ }^{9}$ Hence all patients with ischaemic stroke should be screened either by a 12 -lead ECG or preferably by a 24 -hour Holter recording. Monitoring by implanted loop recorders may be a better monitoring strategy especially for candidates with recurrent transient ischaemic attacks and cryptogenic stroke. ${ }^{10}$

\section{Box 1 Classification of atrial fibrillation according to duration}

\section{Paroxysmal}

Episodes that last less than 7 days, whether they revert spontaneously or undergo direct current cardioversion.

\section{Persistent}

Episodes that continue for more than 7 days and do not self-terminate.

\section{Long-standing}

Continuous for more than 1 year, despite a rhythm-contro strategy.

\section{Permanent}

When the patient and the treating physician decide to accept that the patient will remain in atrial fibrillation and will not attempt to achieve sinus rhythm. Often after a rhythm-control strategy has been unsuccessful. 
Opportunistic screening (pulse check and ECG) of all patients over the age of 65 years in general practice is now strongly recommended by international guidelines. This follows clear demonstrable benefits to increased quality-adjusted life-years and a reduced incidence of stroke. ${ }^{11-13} \mathrm{We}$ may soon have eHealth tools like smartphone ECG devices which might contribute to higher detection rates of silent atrial fibrillation. ${ }^{14,15}$ However, more research is needed before the routine use of these tools. Also, we need more data to establish the burden of atrial fibrillation detected by these devices before starting therapy.

\section{Diagnostic work up}

An ECG is essential to confirm a diagnosis of atrial fibrillation. Additional investigations are needed to determine the cause. All patients should undergo a full blood count, urea and electrolytes and thyroid function tests. An echocardiogram should be performed to detect underlying cardiac abnormalities, such as valvular pathology, left atrial size and volume, as well as the presence of left ventricular dysfunction. In select patients who require acute rhythm control, transoesophageal echocardiography is performed to look for thrombus in the atria before attempting an electrical or pharmacological cardioversion.

\section{Risk stratification tools}

The $\mathrm{CHA}_{2} \mathrm{DS}_{2}$-VASc score is the most widely accepted tool for assessing risk of a stroke in clinical practice and is easy to use. It is endorsed by European ${ }^{13}$ and North American guidelines. ${ }^{16}$ The 2018 Australian atrial fibrillation guidelines recommend a 'sexless' version of the $\mathrm{CHA}_{2} \mathrm{DS}_{2}$-VASc score, known as $\mathrm{CHA}_{2} \mathrm{DS}_{2}$-VA (Table 1). They recommend considering anticoagulation for a $\mathrm{CHA}_{2} \mathrm{DS}_{2}$-VA score of 1 . In contrast, the North American guidelines recommend anticoagulation for a $\mathrm{CHA}_{2} \mathrm{DS}_{2}$ VASc score of at least 2 in men and at least 3 in women. ${ }^{3,16}$ Other risk scores, including ATRIA and ORBIT, do not show major differences in predicting a high risk of stroke.

Bleeding risk can be estimated using the HAS-BLED score (Table 2). ${ }^{17}$ Although higher bleeding risk scores can be used to alert the patient and the doctor, they should not discourage anticoagulation. The net benefit to the patient usually favours stroke prevention with anticoagulation over the risk of major bleeding. ${ }^{3}$ This requires shared decision making with the patient after discussing the risks and benefits of the treatment strategy.

\section{Treatment strategies}

The management of atrial fibrillation revolves around stroke prevention, aggressive risk-factor management, and acute and long-term rate or rhythm control. Catheter ablation may also be considered.

\section{Table 1 The $\mathrm{CHA}_{2} \mathrm{DS}_{2}$-VA score}

\begin{tabular}{|c|c|c|}
\hline C & $\begin{array}{l}\text { Congestive heart failure which includes: } \\
\text { - symptomatic HFrEF and HFpEF } \\
\text { - moderately-severely reduced left ventricular function in the absence of previous symptoms }\end{array}$ & 1 \\
\hline A & Age $\geq 75$ years & 2 \\
\hline D & Diabetes & 1 \\
\hline $\mathbf{S}$ & Previous stroke or transient ischaemic attack or history of systemic thromboembolism & 2 \\
\hline A & Age $65-74$ years & 1 \\
\hline
\end{tabular}

Oral anticoagulation therapy to prevent stroke and systemic embolism is recommended in patients with non-valvular atrial fibrillation whose $\mathrm{CHA}_{2} \mathrm{DS}_{2}-\mathrm{VA}$ score is $\geq 2$ (high quality of evidence), unless there are contraindications to anticoagulation, and should be considered strongly if $\mathrm{CHA}_{2} \mathrm{DS}_{2}$-VA score is 1 (moderate quality of evidence). ${ }^{3}$ 


\section{Table 2 The HAS-BLED score}

\begin{tabular}{|c|c|c|}
\hline Risk factor & Clinical characteristic & Points \\
\hline H & $\begin{array}{l}\text { Hypertension } \\
\text { - systolic blood pressure }>160 \mathrm{mmHg}\end{array}$ & 1 \\
\hline A & $\begin{array}{l}\text { Abnormal liver OR kidney function } \\
\text { - dialysis/renal transplantation/serum creatinine } \geq 200 \mathrm{mmol} / \mathrm{L} \\
\text { - cirrhosis or bilirubin } 2 x \text { upper limit of normal with AST/ALT/ALP } 3 x \text { upper limit normal }\end{array}$ & 1 each \\
\hline $\mathbf{S}$ & Stroke & 1 \\
\hline B & $\begin{array}{l}\text { Bleeding } \\
\text { - history of bleeding or a bleeding diathesis }\end{array}$ & 1 \\
\hline $\mathbf{L}$ & Labile INRs & 1 \\
\hline E & $\begin{array}{l}\text { Elderly } \\
\text { - }>65 \text { years }\end{array}$ & 1 \\
\hline D & $\begin{array}{l}\text { Drugs OR alcohol } \\
\text { - concomitant use of antiplatelets/NSAIDs } \\
\text { - } \geq 8 \text { drinks/week }\end{array}$ & 1 each \\
\hline \multicolumn{3}{|c|}{ HAS-BLED score $\geq 3$ is considered as a high-risk of bleeding } \\
\hline \multicolumn{3}{|c|}{$\begin{array}{l}\text { ALP alkaline phosphatase } \\
\text { ALT alanine aminotransferase } \\
\text { AST aspartate aminotransferase } \\
\text { NSAIDs non-steroidal anti-inflammatory drugs } \\
\text { Source: reference } 17\end{array}$} \\
\hline
\end{tabular}

\section{Stroke prevention}

Anticoagulation reduces the relative risk of stroke by around $70 \%$ in patients with atrial fibrillation. The options include warfarin or direct oral anticoagulant drugs such as factor Xa inhibitors - apixaban and rivaroxaban - and the direct thrombin inhibitor dabigatran. Aspirin is no longer recommended as an alternative.

Direct oral anticoagulants are recommended as first-line therapy over warfarin in patients with nonvalvular atrial fibrillation, provided there are no absolute contraindications to their use (see Box 2). ${ }^{18}$ Dose reduction of direct oral anticoagulants may also be required depending on patient characteristics (see Table 3). ${ }^{3}$ Direct oral anticoagulants are noninferior to warfarin in reducing the risk of stroke and systemic embolism in these patients and have significantly lower rates of major haemorrhage. ${ }^{19}$ Evidence is lacking for their use in patients with mitral stenosis or a metallic valve replacement, hence warfarin is the drug of choice to prevent systemic thromboembolism in this population.

For those receiving warfarin, INR should be measured by routine laboratory tests at least weekly initially and then monthly. Dose modifications of warfarin should be aimed at maintaining the INR between 2 and 3 . When switching from warfarin to a direct oral anticoagulant, after warfarin is stopped, the direct oral anticoagulant can be started when the INR is less than $2 .^{18}$

The expert consensus is that patients with concurrent atrial fibrillation and ischaemic heart disease undergoing percutaneous coronary intervention should receive triple therapy with aspirin, clopidogrel and anticoagulation for as short a time as possible (no longer than six months immediately post percutaneous coronary intervention in stable coronary artery disease). They should then continue dual therapy with clopidogrel and anticoagulation for at least 12 months after percutaneous coronary intervention before considering stopping antiplatelet therapy and continuing anticoagulation as monotherapy. ${ }^{20-23}$ Current evidence does not support substituting clopidogrel with the newer $\mathrm{P}_{2} \mathrm{Y}_{12}$ antiplatelet drugs prasugrel and ticagrelor.

Percutaneous left atrial appendage occlusion may be considered as an option in patients with atrial fibrillation at increased risk of stroke who have contraindications to long-term anticoagulation. This is because of the propensity for bleeding or poor drug tolerance. ${ }^{24}$ 


\section{Box 2 Absolute contraindications to direct oral anticoagulants}

\section{Severe renal impairment:}

- $\mathrm{CrCl}<30 \mathrm{~mL} / \mathrm{min}$ with dabigatran

- $\mathrm{CrCl}<15 \mathrm{~mL} / \mathrm{min}$ with apixaban*

- $\mathrm{CrCl}<15 \mathrm{~mL} / \mathrm{min}$ with rivaroxaban*

Liver impairment e.g. cirrhosis (Child Pugh C)

Current active bleeding or coagulopathy

Previous life-threatening haemorrhage while on a direct oral anticoagulant

Documented previous anaphylaxis to a direct oral anticoagulant

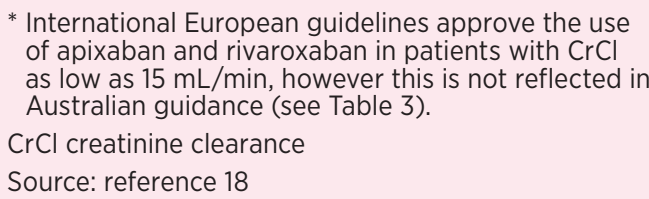

\section{Rate control versus rhythm control}

To date, randomised controlled trials do not suggest superiority of one strategy over the other. ${ }^{25}$

\section{Rhythm control}

Rhythm control may be given priority for:

- those with underlying left ventricular dysfunction

- highly symptomatic patients in spite of ratecontrol therapy

- patient preference (some patients may not want to remain on rate-control drugs because of their symptoms or intolerance to the drugs)

- paroxysmal or early persistent atrial fibrillation.

In the acute setting, any patient who is haemodynamically unstable should undergo immediate synchronised electrical cardioversion. When the patient is haemodynamically stable, acute rhythm control may be desired if they are symptomatic or if it is their first episode with an onset of less than 48 hours. Flecainide and amiodarone are the two drugs available for acute pharmacological cardioversion. ${ }^{26}$

In patients with haemodynamically stable atrial fibrillation lasting more than 48 hours, or of unknown duration, acute rhythm control should be ideally attempted only after anticoagulation for three weeks. Anticoagulation should be continued for at least four weeks after cardioversion. It is still reasonable to attempt an acute cardioversion, only after the transoesophageal echocardiogram has excluded a left atrial thrombus. ${ }^{16}$
Table 3 Dose adjustment of direct oral anticoagulants in non-valvular atrial fibrillation

\begin{tabular}{|c|c|c|}
\hline $\begin{array}{l}\text { Direct oral } \\
\text { anticoagulant }\end{array}$ & Clinical factors & Dose adjustment \\
\hline Apixaban & $\begin{array}{l}\text { At least two of: } \\
\text { - } \text { serum creatinine } \geq 133 \text { micromol/L } \\
\text { - age } \geq 80 \text { years } \\
\text { - weight } \leq 60 \mathrm{~kg}\end{array}$ & $\begin{array}{l}5 \mathrm{mg} \text { twice a day to } \\
2.5 \mathrm{mg} \text { twice a day }\end{array}$ \\
\hline Rivaroxaban & $\begin{array}{l}\text { At least one of: } \\
\text { - } \mathrm{CrCl} 30-49 \mathrm{~mL} / \mathrm{min} \\
\text { - combination with dual antiplatelet therapy }\end{array}$ & $\begin{array}{l}20 \mathrm{mg} \text { daily to } \\
15 \mathrm{mg} \text { daily }\end{array}$ \\
\hline Dabigatran & $\begin{array}{l}\text { At least one of: } \\
\text { - } \mathrm{CrCl} 30-50 \mathrm{~mL} / \mathrm{min} \\
\text { - age } \geq 75 \text { years } \\
\text { - combination with dual antiplatelet therapy }\end{array}$ & $\begin{array}{l}150 \text { mg twice a day to } \\
110 \text { mg twice a day }\end{array}$ \\
\hline
\end{tabular}

$\mathrm{CrCl}$ creatinine clearance

Source: reference 3

Drugs with the strongest evidence for long-term rhythm control are amiodarone, flecainide and sotalol. Given its high adverse-effect profile, amiodarone is reserved for patients who are highly symptomatic with known left ventricular dysfunction when other drugs could be contraindicated. ${ }^{3}$ Flecainide can be started in patients with structurally normal hearts (confirmed with an echocardiogram) who do not have underlying coronary artery disease. Treatment should be started at $50 \mathrm{mg}$ twice a day and titrated up to a maximum dose of $150 \mathrm{mg}$ twice a day, depending on tolerance. Patients should be concomitantly prescribed an atrioventricular nodal blocking drug (e.g. metoprolol) in conjunction with flecainide. Sotalol is also an option for patients intolerant to amiodarone and flecainide. However, the QT interval should be closely monitored, and sotalol is relatively contraindicated in patients with chronic renal impairment.

\section{Rate control}

Treatment options for acute rate control are beta blockers, non-dihydropyridine calcium channel antagonists and amiodarone. Again, amiodarone is reserved for patients who are highly symptomatic with known left ventricular dysfunction when other drugs could be contraindicated.

First-line therapies for long-term rate control, in patients without left ventricular dysfunction, are beta blockers (e.g. metoprolol), non-dihydropyridine calcium channel blockers (e.g. verapamil), or digoxin (with monitoring of serum concentrations). The 
RACE II trial remains the most recent comprehensive evaluation of strict control. ${ }^{27}$ It found that a lenient approach - heart rate target $<110$ beats per minute was not associated with worse outcomes than a stricter approach of $<80$ beats per minute at rest or $<110$ beats per minute with exercise. ${ }^{27}$

In patients with left ventricular dysfunction who are not being considered for rhythm control, or who have failed rhythm control, first-line rate control therapy would be with beta blockers which have survival benefit in heart failure (e.g. bisoprolol, carvedilol, controlled-release metoprolol or nebivolol), or digoxin. Non-dihydropyridine calcium channel blockers are contraindicated in patients with left ventricular dysfunction.

\section{Risk-factor management}

Aggressive management of intercurrent risk factors like obesity, obstructive sleep apnoea, hypertension, diabetes, heart failure, valvular heart disease and excess alcohol is important. ${ }^{6}$ Long-term sustained weight loss reduces the burden of atrial fibrillation and maintains sinus rhythm. ${ }^{28}$ The Australian guidelines therefore endorse intensive weight loss (at least 10\% of body weight) with a target body mass index below $27 \mathrm{~kg} / \mathrm{m}^{2}$.

Exercise is also recommended as it improves aerobic capacity and reduces disease burden. The CARDIOFIT study showed that arrhythmia-free survival with and without rhythm-control strategies was greatest in patients with high cardiorespiratory fitness compared to adequate or low cardiorespiratory fitness. ${ }^{29}$

Australian guidelines ${ }^{3}$ recommend:

- blood pressure no more than $130 / 80 \mathrm{mmHg}$ at rest, and 200/100 $\mathrm{mmHg}$ with exercise

- continuous positive airway pressure therapy if the apnoea-hypopnea index is at least 15/hour
- smoking cessation

- no more than three standard drinks of alcohol per week.

\section{Catheter ablation}

Catheter ablation delivers radiofrequency energy resulting in isolation of the pulmonary veins and other contiguous venous structures. It has been shown to be a successful therapy in patients with atrial fibrillation. ${ }^{30}$ The subgroups that benefit most appear to be patients with paroxysmal and persistent atrial fibrillation who are symptomatic and those with left ventricular dysfunction. ${ }^{31,32}$ Catheter ablation also significantly improves quality of life and is associated with significantly fewer hospital admissions. ${ }^{33}$ It is important to discuss with the patient that procedural success rates vary and $20-30 \%$ of people may require a second procedure within 12 months. Major complication rates from the procedure are $1-7 \%$ and are related to the experience of the operator and the centre. ${ }^{30,31,34}$ The decision to do catheter ablation should be made after a detailed discussion between the patient and the cardiac specialist.

\section{Conclusion}

Treatment strategies for atrial fibrillation include stroke prevention, risk-factor management, rate and rhythm control, and catheter ablation. These have reduced the morbidity and mortality associated with this condition. However, there is growing literature on various aspects of atrial fibrillation management necessitating constant updates for physicians. $<$

Conflict of interest: none declared

\section{REFERENCES}

1. Ball J, Carrington MJ, McMurray JJ, Stewart S. Atrial fibrillation: profile and burden of an evolving epidemic in the 21st century. Int J Cardiol 2013;167:1807-24. https://doi.org/10.1016/j.ijcard.2012.12.093

2. Briffa T, Hung J, Knuiman M, McQuillan B, Chew DP, Eikelboom J, et al. Trends in incidence and prevalence of hospitalization for atrial fibrillation and associated mortality in Western Australia, 1995-2010. Int J Cardiol 2016;208:19-25 https://doi.org/10.1016/j.ijcard.2016.01.196

3. Brieger D, Amerena J, Attia J, Bajorek B, Chan KH, Connell C, et al.; NHFA CSANZ Atrial Fibrillation Guideline Working Group. National Heart Foundation of Australia and the Cardiac Society of Australia and New Zealand: Australian clinical guidelines for the diagnosis and management of atrial fibrillation 2018. Heart Lung Circ 2018;27:1209-66. https://doi.org/10.1016/j.hlc.2018.06.1043

4. Raja DC, Kapoor A. Epidemiology of atrial fibrillation - an Indian perspective. J Assoc Physicians India 2016;64(Suppl):7-10

5. Pathak RK, Mahajan R, Lau DH, Sanders P. The implications of obesity for cardiac arrhythmia mechanisms and management. Can J Cardiol 2015;31:203-10. https://doi.org/ 10.1016/j.cjca.2014.10.027

6. Pathak RK, Middeldorp ME, Lau DH, Mehta AB, Mahajan R, Twomey D, et al. Aggressive risk factor reduction study for atrial fibrillation and implications for the outcome of ablation: the ARREST-AF cohort study. J Am Coll Cardiol 2014;64:2222-31. https://doi.org/10.1016/j.jacc.2014.09.028

7. Enriquez A, Antzelevitch C, Bismah V, Baranchuk A. Atrial fibrillation in inherited cardiac channelopathies: from mechanisms to management. Heart Rhythm 2016;13:1878-84 https://doi.org/10.1016/j.hrthm.2016.06.008

8. Lau DH, Schotten U, Mahajan R, Antic NA, Hatem SN, Pathak RK, et al. Novel mechanisms in the pathogenesis of atrial fibrillation: practical applications. Eur Heart J 2016;37:1573-81. https://doi.org/10.1093/eurheartj/ehv375

9. Freedman B, Potpara TS, Lip GY. Stroke prevention in atrial fibrillation. Lancet 2016;388:806-17. https://doi.org/10.1016/ S0140-6736(16)31257-0

10. Sanna T, Diener HC, Passman RS, Di Lazzaro V, Bernstein RA, Morillo CA, et al.; CRYSTAL AF Investigators. Cryptogenic stroke and underlying atrial fibrillation. N Engl J Med 2014;370:2478-86. https://doi.org/10.1056/ NEJMoa1313600 
11. Aronsson M, Svennberg E, Rosenqvist M, Engdahl J, Al-Khalili F, Friberg L, et al. Cost-effectiveness of mass screening for untreated atrial fibrillation using intermittent ECG recording. Europace 2015;17:1023-9. https://doi.org/ 10.1093/europace/euv083

12. Lowres N, Neubeck L, Redfern J, Freedman SB. Screening to identify unknown atrial fibrillation. A systematic review. Thromb Haemost 2013;110:213-22. https://doi.org/10.1160/ TH13-02-0165

13. Kirchhof P, Benussi S, Kotecha D, Ahlsson A, Atar D, Casadei B, et al.; ESC Scientific Document Group. 2016 ESC Guidelines for the management of atrial fibrillation developed in collaboration with EACTS. Eur Heart J 2016;37:2893-962. https://doi.org/10.1093/eurheartj/ehw210

14. William AD, Kanbour M, Callahan T, Bhargava M, Varma N, Rickard J, et al. Assessing the accuracy of an automated atrial fibrillation detection algorithm using smartphone technology: The iREAD Study. Heart Rhythm 2018;15:1561-5. https://doi.org/10.1016/j.hrthm.2018.06.037

15. Turakhia MP, Desai M, Hedlin H, Rajmane A, Talati N, Ferris T, et al. Rationale and design of a large-scale, app-based study to identify cardiac arrhythmias using a smartwatch: the Apple Heart Study. Am Heart J 2019;207:66-75. https://doi.org/10.1016/j.ahj.2018.09.002

16. January CT, Wann LS, Calkins H, Chen LY, Cigarroa JE, Cleveland JC Jr, et al. 2019 AHA/ACC/HRS focused update of the 2014 AHA/ACC/HRS Guideline for the Management of Patients With Atrial Fibrillation: a report of the American College of Cardiology/American Heart Association Task Force on Clinical Practice Guidelines and the Heart Rhythm Society in collaboration with the Society of Thoracic Surgeons. Circulation 2019;140:e125-51. https://doi.org/ 10.1161/CIR.0000000000000665

17. Pisters R, Lane DA, Nieuwlaat R, de Vos CB, Crijns HJ, Lip GY. A novel user-friendly score (HAS-BLED) to assess 1-year risk of major bleeding in patients with atrial fibrillation: the Euro Heart Survey. Chest 2010;138:1093-100. https://doi.org/10.1378/chest.10-0134

18. Heidbuchel H, Verhamme P, Alings M, Antz M, Hacke W, Oldgren J, et al.; European Heart Rhythm Association. European Heart Rhythm Association Practical Guide on the use of new oral anticoagulants in patients with non-valvular atrial fibrillation. Europace 2013;15:625-51. https://doi.org/ 10.1093/europace/eut083

19. Ruff CT, Giugliano RP, Braunwald E, Hoffman EB, Deenadayalu N, Ezekowitz MD, et al. Comparison of the efficacy and safety of new oral anticoagulants with warfarin in patients with atrial fibrillation: a meta-analysis of randomised trials. Lancet 2014;383:955-62. https://doi.org/10.1016/S0140-6736(13)62343-0

20. Gibson CM, Mehran R, Bode C, Halperin J, Verheugt F, Wildgoose P, et al. An open-label, randomized, controlled, multicenter study exploring two treatment strategies of rivaroxaban and a dose-adjusted oral vitamin $\mathrm{K}$ antagonist treatment strategy in subjects with atrial fibrillation who undergo percutaneous coronary intervention (PIONEER AF-PCI). Am Heart J 2015;169:472-8.e5. https://doi.org/ 10.1016/j.ahj.2014.12.006

21. Cannon CP, Bhatt DL, Oldgren J, Lip GY, Ellis SG, Kimura T, et al.; RE-DUAL PCI Steering Committee and Investigators. Dual antithrombotic therapy with dabigatran after $\mathrm{PCl}$ in atrial fibrillation. N Engl J Med 2017;377:1513-24. https://doi.org/10.1056/NEJMoa1708454

22. Lopes RD, Heizer G, Aronson R, Vora AN, Massaro T, Mehran R, et al.; AUGUSTUS Investigators. Antithrombotic therapy after acute coronary syndrome or $\mathrm{PCl}$ in atrial fibrillation. N Engl J Med 2019;380:1509-24. https://doi.org/ 10.1056/NEJMoa1817083
23. Janardan J, Gibbs H. Combining anticoagulation and antiplatelet drugs in coronary artery disease. Aust Prescr 2018;41:111-5. https://doi.org/10.18773/austprescr.2018.039

24. Pison L, Potpara TS, Chen J, Larsen TB, Bongiorni MG, Blomström-Lundqvist C; Scientific Initiative Committee, European Heart Rhythm Association. Left atrial appendage closure-indications, techniques, and outcomes: results of the European Heart Rhythm Association Survey. Europace 2015;17:642-6. https://doi.org/10.1093/europace/euv069

25. Chatterjee S, Sardar P, Lichstein E, Mukherjee D, Aikat S. Pharmacologic rate versus rhythm-control strategies in atrial fibrillation: an updated comprehensive review and metaanalysis. Pacing Clin Electrophysiol 2013;36:122-33. https://doi.org/10.1111/j.1540-8159.2012.03513.x

26. Chevalier P, Durand-Dubief A, Burri H, Cucherat $M$, Kirkorian G, Touboul P. Amiodarone versus placebo and class Ic drugs for cardioversion of recent-onset atrial fibrillation: a meta-analysis. J Am Coll Cardiol 2003;41:255-62. https://doi.org/10.1016/S0735-1097(02)02705-5

27. Van Gelder IC, Groenveld HF, Crijns HJ, Tuininga YS Tijssen JG, Alings AM, et al.; RACE II Investigators. Lenient versus strict rate control in patients with atrial fibrillation. N Engl J Med 2010;362:1363-73. https://doi.org/10.1056/ NEJMoa1001337

28. Pathak RK, Middeldorp ME, Meredith M, Mehta AB, Mahajan R, Wong CX, et al. Long-term effect of goaldirected weight management in an atrial fibrillation cohort: a long-term follow-up study (LEGACY). J Am Coll Cardiol 2015;65:2159-69. https://doi.org/10.1016/j.jacc.2015.03.002

29. Pathak RK, Elliott A, Middeldorp ME, Meredith M, Mehta AB, Mahajan R, et al. Impact of CARDIOrespiratory FITness on arrhythmia recurrence in obese individuals with atrial fibrillation: The CARDIO-FIT Study. J Am Coll Cardiol 2015;66:985-96. https://doi.org/10.1016/j.jacc.2015.06.488

30. Ganesan AN, Nandal S, Lüker J, Pathak RK, Mahajan R, Twomey D, et al. Catheter ablation of atrial fibrillation in patients with concomitant left ventricular impairment: a systematic review of efficacy and effect on ejection fraction. Heart Lung Circ 2015;24:270-80. https://doi.org/10.1016/ j.hlc.2014.09.012

31. Marrouche NF, Brachmann J, Andresen D, Siebels J, Boersma L, Jordaens L, et al.; CASTLE-AF Investigators. Catheter ablation for atrial fibrillation with heart failure. N Engl J Med 2018;378:417-27. https://doi.org/10.1056/ NEJMoa1707855

32. Packer DL, Mark DB, Robb RA, Monahan KH, Bahnson TD, Poole JE, et al. CABANA Investigators. Effect of catheter ablation vs antiarrhythmic drug therapy on mortality, stroke, bleeding, and cardiac arrest among patients with atrial fibrillation: the CABANA randomised clinical trial. JAMA 2019;321:1261-74. https://doi.org/10.1001/jama.2019.0693

33. Mark DB, Anstrom KJ, Sheng S, Piccini JP, Baloch KN, Monahan $\mathrm{KH}$, et al.; CABANA Investigators. Effect of catheter ablation vs medical therapy on quality of life among patients with atrial fibrillation: the CABANA randomized clinical trial. JAMA 2019;321:1275-85. https://doi.org/10.1001/ jama.2019.0692

34. Verma A, Jiang CY, Betts TR, Chen J, Deisenhofer I, Mantovan R, et al.; STAR AF II Investigators. Approaches to catheter ablation for persistent atrial fibrillation. N Engl J Med 2015;372:1812-22. https://doi.org/10.1056/ NEJMoa1408288 